\title{
Highlights of Dutch and US coastal graduation projects in the Mississippi Delta after Hurricane Katrina
}

\author{
M. van Ledden ${ }^{1,3}$, M. Kluyver ${ }^{2}$, A.J. Lansen ${ }^{1}$ and R. Kluskens ${ }^{1}$ \\ ${ }^{1}$ Royal Haskoning, George Hintzenweg 85, Rotterdam, The Netherlands, m.vanledden@royalhaskoning.com \\ ${ }^{2}$ Moffatt \& Nichol, 301 Main Street, Suite 800, Baton Rouge, LA 70825, USA \\ ${ }^{3}$ Delft University of Technology, Stevinweg 1, Delft, The Netherlands
}

\begin{abstract}
This paper presents the highlights of coastal graduation projects conducted in New Orleans after Hurricane Katrina from students of universities in The Netherlands (Delft, Twente, Groningen, Amsterdam, Wageningen) and Louisiana (LSU, UNO). The intent is to show good examples of how knowledge and modeling tools in the field of coastal engineering, typical to the Netherlands, is applied in an international context. Three illustrative examples are summarized. The first example is the development of an innovative forecasting tool for predicting storm surge in the Louisiana coastal zone. This tool has successfully been applied during training exercises and reallife applications in New Orleans. Second, an in-depth study has been carried out to increase the understanding of the effectiveness of diversions to restore wetlands. Practical recommendations were provided for the choice of location and size of diversions in the Lower Mississippi. A third example is the long-term morphological modeling of the Wax Lake Delta. Various characteristics of this delta development were reproduced by the model, but also limitations of the predictive performance of the model were detected. This paper will close with an outlook on further collaboration between Louisiana and The Netherlands.
\end{abstract}

\section{INTRODUCTION}

In 2005 Hurricane Katrina showed the Gulf Coast's extreme vulnerability to coastal flooding. After the first landfall in Florida, Hurricane Katrina intensified to a Category 5 hurricane in the Gulf of Mexico. The second landfall took place near Buras in Louisiana. It generated storm surge levels at the coast with a maximum water level of 9m+MSL near Biloxi (Mississippi). Over 50 breaches in the levee system around New Orleans resulted in major flooding of the city. With a total property damage estimated at $\$ 81$ billion (2005), it was the costliest natural disaster in US history, and 1836 people lost their lives in this tragedy.

The coastal flooding during Katrina has initiated various federal and state programs to reduce flood risk in this area. The US Army Corps of Engineers has been responsible for executing a program to improve the levee system around New Orleans to the 100-yr design standard. This 6-year program was focusing on flood risk reduction in the short term and has resulted in a $\$ 15$ billion investment program in levees, pump stations and storm surge barriers to provide the necessary level of protection.

The Louisiana Coastal Protection and Restoration Project (LACPR) from the US Army Corps of Engineers and Louisiana's Comprehensive Master Plan for a Sustainable Coast from the State of Louisiana have been focusing on the long-term flood risk reduction. A range of measures were evaluated for different levels of protection. These measures included structural measures such as the further raising of levees and barriers but also a range of non-structural measures such as wetland restoration, evacuation and changing building codes to further reduce flood risk. Both projects have resulted in various flood risk reduction strategies for coastal Louisiana.

According to the authors, these programs have provided a unique opportunity for students to experience how people in this delta gain their livelihoods from the resources of the coast and how they are dependent on manmade flood protection infrastructure and the natural coastal habitat that protect their homes and business from storm flooding. About 20 graduation projects have been initiated with Dutch and US students on various coastal engineering topics in and around New Orleans and in the Mississippi River Delta. These students originated from various universities in The Netherlands (Delft, Twente, Groningen, Amsterdam, Wageningen) and Louisiana (UNO, LSU).

This paper shows highlights of coastal graduation projects in Louisiana. Three illustrative examples are summarized from the coastal graduation projects on how knowledge and modeling tools in the field of coastal engineering, typical to the Netherlands, are applied in an international context. These examples are focusing on two central coastal challenges in Louisiana: hurricane storm surge and wetland restoration. This paper will close with a discussion of coastal research topics for further collaboration between Louisiana and The Netherlands.

\section{HURRICANE SURGE FORECASTING}

As a coastal city, New Orleans is threatened by tropical storms or hurricanes every year. Both intense hurricane force winds and associated high water levels (storm surges) threaten this city. After Hurricane Katrina flooded the majority of the city in 2005, there has been a keen interest to obtain better insight into the storm surges produced by tropical systems. In order to adequately protect and prepare the city of New Orleans, forecasted surge levels for an approaching storm could provide a crucial piece of information. Forecasted surge levels are necessary to make decisions about safety measures, distribution of information to the public, evacuation of residents and emergency sandbag placement.

To predict these surge levels, the U.S. Army Corps of Engineers 


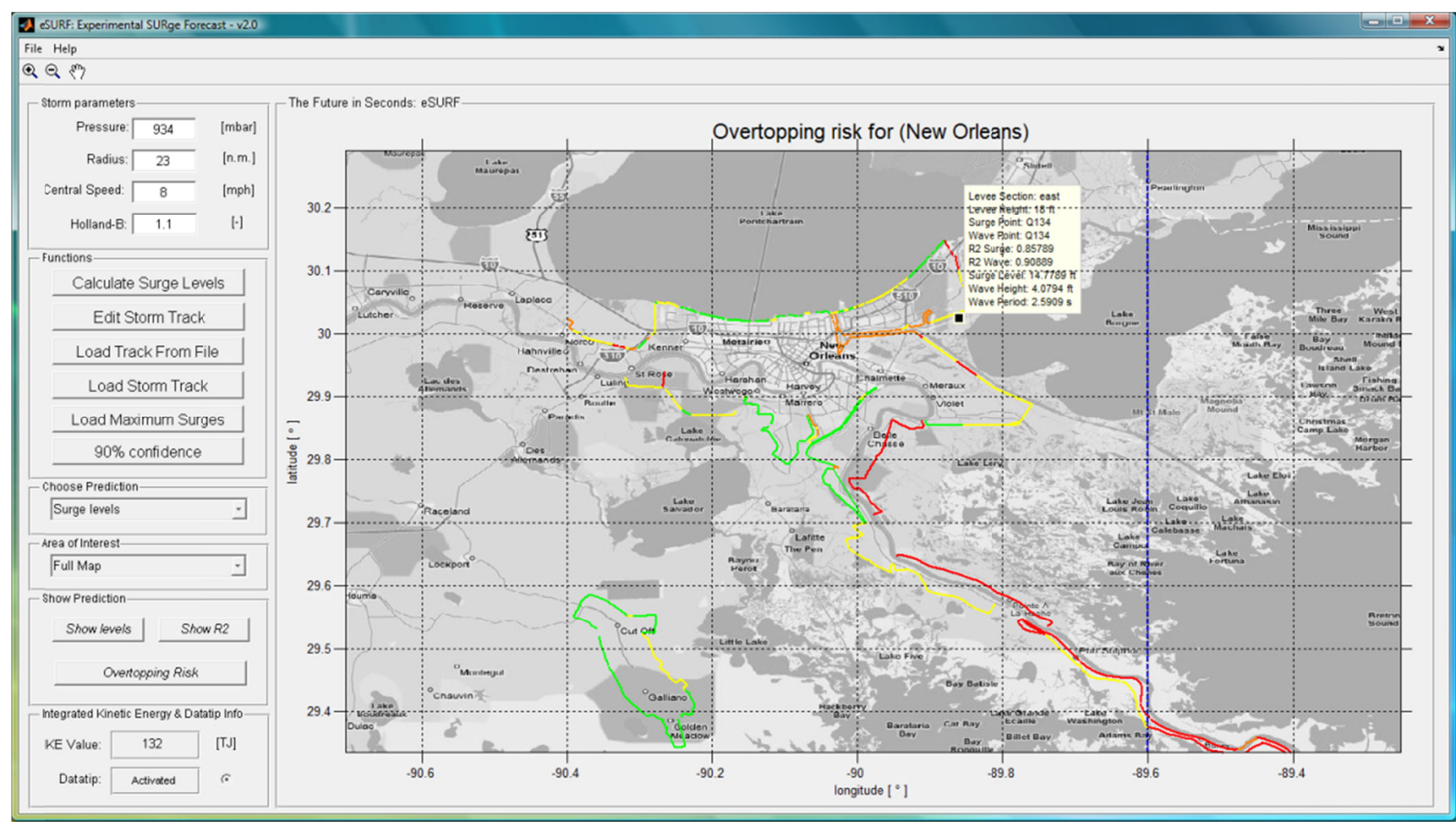

Figure 1. Overtopping risk for the New Orleans Hurricane Risk Reduction System

(USACE) utilizes the ADCIRC model (see e.g. Westerink et al. 2008), a numerical model that calculates free surface elevation due to tides, winds, river discharges, precipitation and more. The ADCIRC model captures the physical processes during a storm event to a high level of detail.

The ADCIRC model is physically very detailed, and almost all relevant aspects regarding hurricanes and storm surge are used to create a forecast. This however comes at a certain cost. The high level of detail requires a computer to do a significant amount of calculations. Depending on the complexity of the storm and used (super)computer resources, it could take ADCIRC more than 6 hours to finalize a single model run. Due to the changeable nature of these complicated weather systems, a hurricane may already have completely changed in size or its course within the time frame to complete a model run.

The goal of the eSURF project was to make a fast forecasting model that can predict surge levels caused by hurricanes. eSURF stands for Experimental Surge Forecast. Van den Berg (2008), Lin (2009) and Smits (2009) worked on the project and through various stages of iteration developed the program in the attempt to reduce the dependency on elaborate, time consuming model calculations in the critical hours before a Hurricane makes landfall. Their contributions during their graduation projects resulted in the eSURF program that can now make a surge level prediction in seconds, without significant reductions in accuracy. The program uses an innovative algorithm to come up with a fast and relative accurate prediction of surge levels. The model is a prediction model that uses multiple linear regression on a dataset of model results. At the base are the ADCIRC results from 152 synthetic storms for the Louisiana coast, 2566 surge level prediction points, the parameters of the forecasted hurricane and the eSURF algorithm. In addition, eSURF can also predict wave heights and wave periods and provide a risk classification based upon the forecasted hydraulic parameters in combination with known levee heights for the Greater New Orleans Metropolitan area (Figure 1).

The user-friendly interface created by the students, at last, makes the program accessible to anyone with basic coastal engineering skills and a desktop computer. The eSURF project provided an opportunity for students to perform an in-depth study of the physical processes of hurricanes and storm surge and its relevancy to society. The contribution of the students to the project has been greatly appreciated. The USACE can use this tool in conjunction with other sources of information available prior to a storm making landfall. The multitude of sources available helps to establish a better informed and more reliable risk assessment. Future development of eSURF includes the expansion of the programs use to all neighboring states situated on the Gulf of Mexico.

\section{WETLAND RESTORATION}

The wetlands of Louisiana are a unique habitat with high ecological, recreational and economical value. The marshes and swamps of South-Eastern Louisiana are, however, deteriorating at an alarming rate. In the past, the Mississippi River was able to carry sediment to the marshes every flood season, but now the river is isolated from its floodplains because of human interventions. Over the years, a levee system has been built, alongside the downstream portion of the Mississippi River to prevent flooding of the adjacent land. The river mouth is confined to a number of canalized channels protruding into the Gulf of Mexico, and sediment is therefore immediately delivered to the 
edge of the continental shelf, isolated from the current bird foot shaped sub-delta and the up and down-drift coasts of the deltaic plain. The sediment deposits off the continental shelf and is no longer replenished into the marshes. Furthermore, increased rates of subsidence in the region have been correlated to withdrawal of hydrocarbons and groundwater in the delta plain. The relative sealevel rise in this region is at a rate of $10 \mathrm{~mm}$ per year. The result is a staggering loss of marshland over the past century.

The impact of the marshland degradation on the attractiveness and sustainability of the Louisiana coastal plain is significant. It is predicted that hurricane surge elevations at the toe of the Greater New Orleans levee system will increase substantially if the process of wetland degradation continues at the current rate. Therefore, a long term investment to protect the great city of New Orleans is to start revitalizing the marsh area of Southern Louisiana. Allowing river water rich with sediments to enter the marshes through diversions is considered to be a promising option which could slow down or even reverse this trend. Both the work from Hillen et al. (2007) in this section and Hanegan (2011) in the next section focus on this option.

Hillen et al. (2007) studied the feasibility and effects of marsh restoration by a diversion in the Mississippi River near Port Sulphur (see Figure 2 for locations), diverting water into the adjacent Barataria Bay and Breton Sound. The main research objective was to determine the land building potential of a diversion in the Mississippi River near Port Sulphur and if accreted land will contribute to surge reduction and a safer New Orleans in the long term. The subject has been studied with a qualitative physical model and detailed numerical simulations with a quantitative $3 \mathrm{D}$ numerical model.

A literature survey showed that there still is a knowledge gap on the subject of engineering large scale effective sediment diversion. Some of the diversions built in the past along the Mississippi River work well, while others do not function as originally planned. The reasons of malfunctioning and the complex physical processes are not well understood. Another knowledge gap is the complex interaction between marshes and storm surge propagation and the effect of marshes on the storm surge reduction. A historical rule-of-thumb exists from USACE (1963) for surge level reduction over marshes (ca. $1 \mathrm{~m}$ per $14.5 \mathrm{~km}$ ) but various researchers utilizing detailed numerical computations show that the effect of marshes for extreme events is limited (see e.g. Resio and Westerink, 2008).

First-order calculations for the Port Sulpher project area show that a significant amount of water needs to be diverted from the Mississippi River to introduce sufficient sediment into the system for substantial marsh restoration. It was estimated that a yearly average discharge through the diversion of approximately 50.000 $\mathrm{m}^{3} / \mathrm{s}$ is needed. This is about one third of the total yearly average Mississippi River discharge. Although these effects have not been quantified in detail, it is safe to state that such a large change in the hydrodynamics would have an effect on the salinity intrusion and morphodynamics of the Mississippi River.

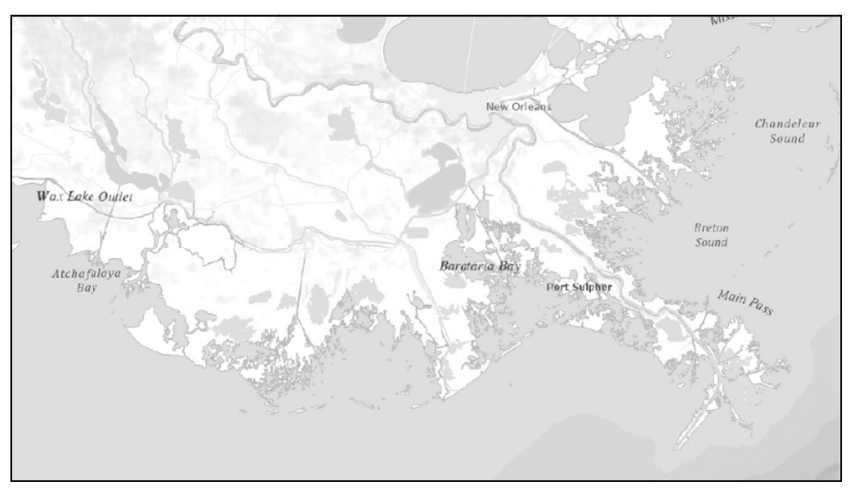

Figure 2. South Eastern Louisiana with the Mississippi Delta and the Atchafalaya Basin and Delta (including the Wax Lake Outlet) in the West

To gain insight in the influence zone and possible effects of a diversion, a physical model at the Louisiana State University (LSU) was utilized. This physical model represents the lower part of the Mississippi River Delta (The Birdfoot Delta). Model runs simulated changes over a 30 year time frame for three different diversions. The students were able to study the influence zone of a diversion and the sediment movement through the river. The model indicated that the location and orientation of a diversion in the river are important factors that need to be taken into consideration when designing a diversion. The data obtained from the physical model was used as input for more detailed calculations with a numerical model.

For quantitative modeling on storm surge reduction, the numerical modeling suite Delft3D was used. Several model runs with different schematizations of the project area were completed. Boundary conditions were based on the storm conditions of hurricane Katrina to provide a first insight and to study possible effects on a case by case basis. The modeled storm surge levels for the base conditions are higher than the actual measured storm surges. However, this model does approximate the results of the actual storm surge and can, therefore, be used to determine relative effects of storm surge reduction of the marsh area created by a diversion near Port Sulphur.

Different scenarios which represient various marsh types are modeled: the existing situation, a situation with an area of solid marshes, a marsh area with $35 \%$ open water, a marsh area with canals, a gently sloped marsh area and a shallow water area. The increased roughness and vegetation parameters are applied in a special vegetation (marsh) module of the model. The model results show that marshes do have a positive effect on storm surge reduction. The influence area of the marshes on storm surge is limited to the Mississippi Birdfoot, and there is no storm surge reduction in Lake Borgne or Lake Pontchartrain. The model shows that the storm surge reduction is identical for solid marshes and for marshes with canals or marsh areas with $35 \%$ open water. For Hurricane Katrina type conditions, $30 \mathrm{~km}$ of marshland will reduce the storm surge elevation by about $0.5 \mathrm{~m}$ to $1 \mathrm{~m}$.

Hillen et al. (2007) showed that creating a large-scale sediment diversion to increase the long-term safety of New Orleans and its surrounding areas is a promising possibility but also identified its challenges. Substantial amounts of sediment rich water need to be diverted from the main channel to slow down or reverse marsh degradation. This will in turn affect the river bed morphology and 
could have an impact on the shipping function of the main channel. It is recommended to study this effect in more detail.

If enough sediment is diverted from the Mississippi River, land building and marsh restoration will occur which in turn can reduce storm surge levels. The storm surge reduction is primarily of local nature and depends largely on the characteristics of the storm, such as path and storm intensity. For this case study, marshes that will be created by the diversion near Port Sulphur will locally reduce the storm surge and therefore increase the safety of the residents of Plaquemines Parish. These marshes do not directly lead to a reduction in the storm surge levels near New Orleans. If no interventions occur in coastal Louisiana, the marsh deterioration will continue at the current alarming rate and because this deterioration is at such a high rate and in such a large area, it will severely reduce the storm surge reduction capacity of the Mississippi deltaic plain in the long term. A large-scale diversion is a good option as a sustainable part of a long-term master plan for the future of New Orleans and its surroundings.

\section{WAX LAKE DELTA MORPHOLOGY}

Hanegan (2011) also focused on the option of constructing diversions to restore marshlands. His focus was the delta formation over long-term timescales taking place after the construction of a river diversion. The most beneficial impact of an outlet to the marsh area depends on the formation of a new delta at the seaward side of the outlet by deposition of diverted sediment. In his thesis work "Modeling the Evolution of the Wax Lake Delta in Atchafalaya Bay, Louisiana", the results of process-based, hydrodynamic and morphologic modeling using Delft3D are presented, focusing on the Wax Lake Delta in Atchafalaya Bay. The model was developed to simulate a five year period of delta development from the beginning of 1998 to the end of 2002. The purpose of this modeling study was to further validate the ability of process-based modeling tools to successfully simulate typical delta-building processes and the resulting morphologic and stratigraphic characteristics of such a delta. With the ability to reliably predict the resulting deltaic deposition, the investments in the outlets for restoration of the Louisiana marshlands can be optimized.

The model applied in this study was generally successful in simulating the growth typical of river dominant systems (Figure 3). The Wax Lake Delta is clearly river-dominant according to traditional classification schemes; however, the deposition of fine sediments is influenced by basin processes that resuspend and export significant quantities from the Atchafalaya Bay. The processes contributing to the coarse sediment depositional features that dominate the Wax Lake Delta are qualitatively simulated under purely riverine forcings, but the fine sediment dynamics cannot be accurately simulated in the present, process-limited model. Recommendations for improving morphological simulation include model redevelopment with an alternative, total load transport formulation and the inclusion of limited marine forcings that inhibit fine-sediment deposition.

The accurate simulation of the actual development of a real delta requires a corresponding accurate representation of dominant processes, model domain bathymetry and sediment composition, and the calibration of hydrodynamics and sediment transport.
Though the hydrodynamic calibration process was fairly straightforward, the subsequent need to alter calibrated sediment transport parameters for more accurate long-term simulation highlights the difficulty of transport calibration based on a single, discrete measured event. In this case, the possible storage of fine sediment in the prototype upstream channel during low flows, hysteresis in transport and discharge peaks at the upstream boundary, and the limited model representation of marine processes create significant complications for calibration.

The results of this study indicate that successful simulation of delta development along the typically low-energy Louisiana coast requires inclusion of marine processes beyond those included in this assumed river-dominant simulation. The inclusion of two sediment fractions, necessary to assess the validity of depositional body stratigraphy, likely results in a less accurate morphologic simulation than if only the coarse sediment fraction was included because of the neglected processes and their effect on fine sediment deposition. Though it was thought that the use of process-based, depth-averaged morphological modeling in Delft3D would offer an ideal method for assessing the expected land-building arising from large-scale sediment diversions in the transgressive Mississippi Delta, the necessary inclusion of multiple marine processes for accurate delta development simulation, especially the difficult to implement wind forcings from periodic cold front passages, makes the use of this modeling technique somewhat inefficient. At the moment, more simplified models that assume delta radial symmetry are more suited for the evaluation of expected diversion land-building for preliminary studies where multiple location alternatives are still in consideration. Detailed process-based modeling, such as that presented in this study, is more suited for much higher level evaluations in the diversion design process that justify the increased effort to adequately represent all processes involved. For situations in which the exact stratigraphy of depositional bodies is of no interest, simulation of the development of the mostly sanddominant delta features in the Southeast Louisiana Coast may be more efficiently achieved with a single fraction sediment schematization.

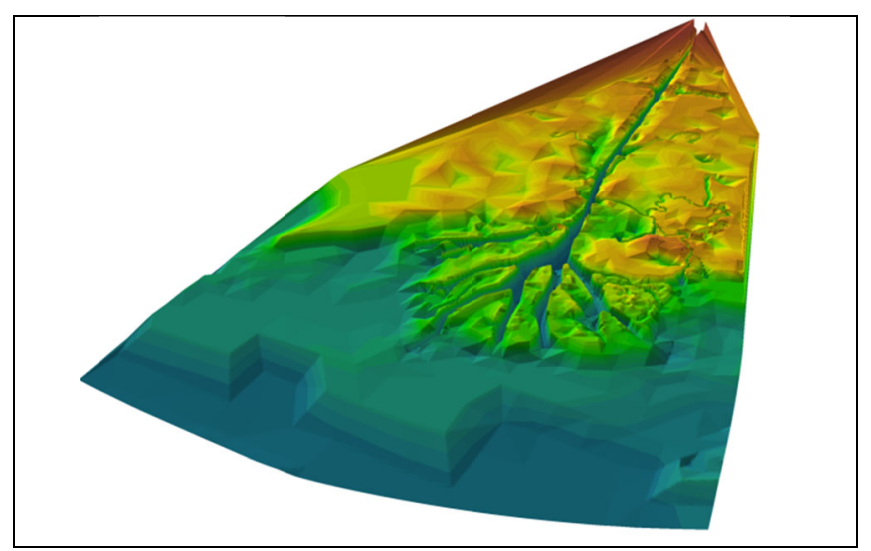

Figure 3. Bathymetry and typical ebb-delta features of the river dominant Wax Lake Delta 


\section{OUTLOOK}

In the aftermath of Hurricane Katrina, New Orleans and the Mississippi River Delta Region has invested more money than any time in history of the State of Louisiana in rebuilding levees and wetlands. This investment has nourished world class science, research and engineering expertise in which the Dutch Coastal Engineering community and its students have taken part. This paper has shown three examples of graduation projects after Katrina by Dutch and US students. The projects have been welcomed with high interest by local stakeholders because of the high quality and innovative ideas.

Now is the time to use this momentum to continue the exchange of students and build upon academic and scientific relationships. Especially in light of the just published Louisiana's Master Plan for a sustainable Coast (State of Louisiana, 2012), this is a solid foundation on which the State plans to continue building Louisiana's Coastal Program. Within the plan, structural and nonstructural projects and programs are proposed, many of which have been conceptually studied by the Dutch students with a few selected for more in depth study (e.g. river diversions).

As Louisiana moves forward with the implementation of the Master Plan and associated in-depth research of feasibility of the proposed projects within the plan, the exchange of Dutch and US students should be continued in our view. Potential topics for further collaboration are:

- $\quad$ System interaction between river and marshes. Long-term strategies for the coast of Louisiana include marsh restoration and its interaction with the Mississippi River and its tributaries. Balancing the needs for redistribution of fresh water and sediments through diversions should be weighed against other important (economical) functions of the Mississippi River. Dutch expertise in River Management and supporting modeling tools can support weighing of various interests and alternatives.

- Long-term morphology of the Louisiana Coast. The morphology of the coastline is governed by various marine and alluvial processes which are complex in nature. The impact of human interventions of any sort need to be studied for optimization of any coastal strategy. The Dutch knowledge and experience in both short-term and longterm coastal modeling can play a key role in evaluating and optimizing these interventions.

- $\quad$ Hurricane surge prediction. Emergency Management will be a major subject in the overall flood protection strategy of the Southern Louisiana coastal region, in which accurate prediction will highly impact the effectiveness of any emergency measure. The Dutch knowledge in modeling of storm surges and the experience in operational flood forecasting can be shared with the Louisiana coastal community to improve emergency management

Climate change and the challenges it poses to society are making newspaper headlines in not only The Netherlands and Louisiana, but in many coastal communities. With increasing globalization of research and consultancy services students should be part of the international dialogue in an early stage to familiarize and offer them a global perspective on the international coastal engineering community.

\section{ACKNOWLEDGEMENT}

The editors thank the students for their enormous enthusiasm and motivation shown during their projects. It has been rewarding to work with high-talented and very motivated students during their projects in New Orleans. The students hosted in New Orleans projects were (in alphabetical order): Marcel van de Berg, Anja Bos, Tjeerd Driessen, Kevin Hanegan, Sanne van de Heuvel, Marten Hillen, Freek Kranen, Jos Kuilboer, ChuHui Lin, Alissa Miller, Pieter Nordbeck, Tom Smits, Roald Treffers, Mats Vosse and Marcel van der Waart. The US Army Corps of Engineers in New Orleans is highly acknowledged for hosting the Dutch students. The discussions at the New Orleans District have been very fruitful and enriched the projects to a large extent. The financial and logistical support from Royal Haskoning is highly appreciated.

\section{REFERENCES}

Hanegan, K., Modeling the evolution of the Wax Lake Delta in Atchafalaya Bay, Louisiana, Erasmus Mundus Msc Programme, Coastal and Marine Engineering and Management (CoMeM), 2011.

Hillen, M., Kuilboer, J., Nordbeck, P., Treffers, R. The effects of a diversion in the Mississippi River near Port Sulphur on the long-term safety of New Orleans, Delft University of Technology, 2007.

Lin, C. The future in seconds: eSURF, University of Twente, 2009.

Resio, D.T., and J.J. Westerink, "Modeling the physics of storm surges", Physics Today, September 2008, pp. 33-38.

Smits, T., Internship Report - Internship at Royal Haskoning in New Orleans, Delft University of Technology, 2009.

State of Louisiana, Louisiana's Master Plan for a sustainable Coast (draft), http://www.coastalmasterplan.louisiana.gov/2012master-plan/draft-2012-master-plan/, 2012.

US Army Corps of Engineers, US Army Engineer District, New Orleans, Interim Survey Report, Morgan City, Louisiana and Vicinity, serial no. 63, US Army Engineer District, New Orleans, LA (November 1963).

Van Den Berg, M. A predictive model for hurricane surge levels in New Orleans, University of Twente, 2008.

Westerink, J. J., J. C. Feyen, J. H. Atkinson, H. J. Roberts, E. J. Kubatko, R. A. Luettich, C. Dawson, M. D. Powell, J. P. Dunion, and H. Pourtuheri (2008), A basin- to channel-scale unstructured grid hurricane storm surge model applied to southern Louisiana, Mon. Weather Rev., 136, 833-864, doi:10.1175/2007MWR1946.1. 